\title{
APPARATUS FOR FRACTIONAL DISTILLATION ${ }^{\prime}$
}

BY C. W. YoLw:

THIS apparatus for fractional distillation of mixtures of liquids of different boiling points is constructed on the

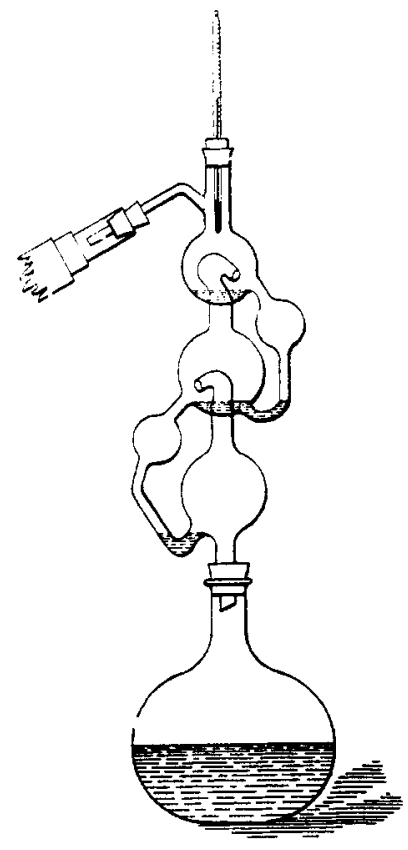

dephlegmator principle. Although the opening of the recurved main tube is never closed by the condensed liq. uid, comparatively only small quantities of rapors of the liquids, condensable in the respective bulbs, ascend or ultimately escape in the condenser, so that by a second distillation liquids of practically uniform boiling points are obtained.

I have used this apparatus for the preparation of paraffins and benzene derivatives, and can recommend it as a good and practical instrument. The principle employed is evident from the figure, and any glass blower can make it. 